\title{
Rate of improvement of pulmonary function in sarcoidosis during treatment with corticosteroids
}

\author{
DAVID S GOLDSTEIN, M HENRY WILLIAMS
}

From the Bronx Municipal Hospital Center and the Pulmonary Division, Albert Einstein College of Medicine, New York

ABSTRACT Serial measurements of vital capacity were obtained in 11 patients with impaired pulmonary function due to sarcoidosis during 12 courses of corticosteroid treatment. Vital capacity improved promptly and approached a maximum value in about three weeks. A three week trial is probably sufficient to show whether or not corticosteroids are effective in a patient with sarcoidosis.

Several studies have shown that when pulmonary function is impaired in sarcoidosis there is likely to be considerable improvement after the start of treatment with corticosteroids. ${ }^{1-3}$ Whether or not such treatment is warranted in the absence of symptomatic benefit from the drug is a matter of debate; but there is evidence that improvement of lung function can be maintained, although this may require months or years of treatment. ${ }^{4-6}$ In embarking on such treatment physicians frequently use the initial improvement of lung function as an indication of benefit. There are no data on the rate of improvement that occurs with steroid treatment and such information would be useful in assessing the effects of treatment in planning long term management.

Although impairment of diffusion is the most sensitive indicator of the diffuse interstitial disease that occurs in sarcoidosis, improvement arising from corticosteroid treatment is better reflected in increase of the vital capacity. ${ }^{2}$ For this reason, to learn more about the rate of improvement of lung function that occurs in sarcoidosis we elected to make frequent measurements of vital capacity in a group of patients deemed likely to respond to steroid treatment.

\section{Methods}

Eleven patients with pulmonary sarcoidosis proved by biopsy and abnormal pulmonary function were treated with systemic steroids $(40 \mathrm{mg}$ of prednisone daily or its equivalent). The principal indication for

Address for reprint requests: Dr $M$ Henry Williams jun, Chest Service, Bronx Municipal Hospital Center, Van Etten Hospital, Room 3A4, Pelham Parkway and Eastchester Road, Bronx, New York 10461, USA.

Accepted 2 December 1985 treatment was impaired pulmonary function at the time of initial evaluation. All patients had vital capacity and diffusing capacity measurements that were moderately to severely reduced (table). $\mathrm{FEV}_{1} /$ vital vital

capacity

(l)

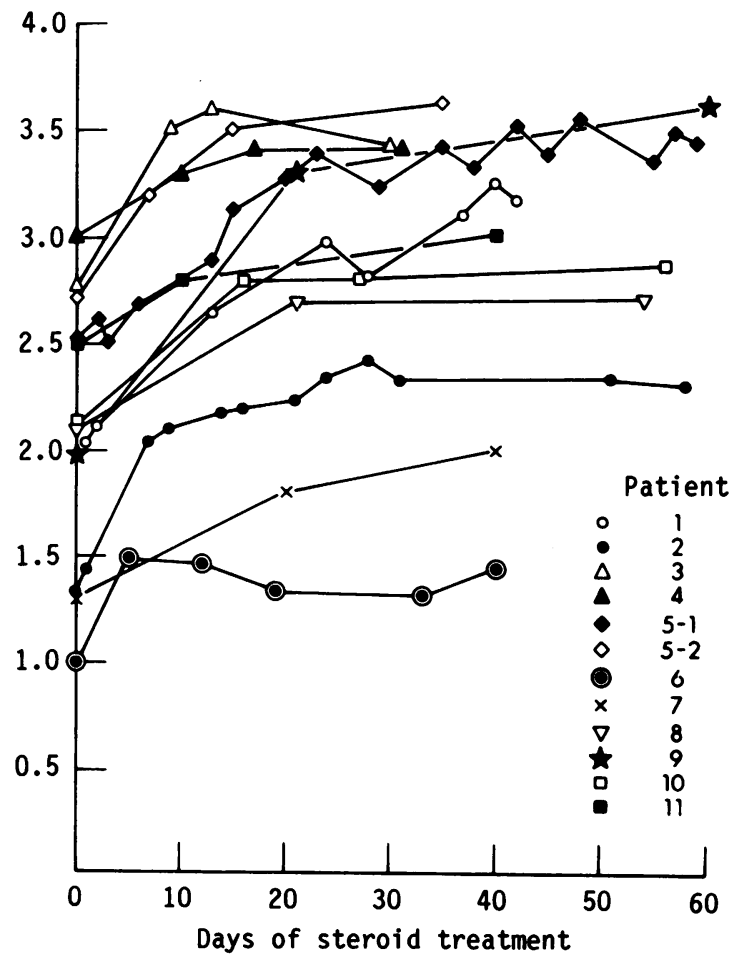

Improvement in vital capacity in the 11 patients related to duration of steroid treatment. 
Lung function of the 11 patients before treatment

\begin{tabular}{|c|c|c|c|c|c|c|c|c|}
\hline $\begin{array}{l}\text { Patient } \\
\text { No }\end{array}$ & Age & Sex & $\begin{array}{l}V C \\
(l)\end{array}$ & $\begin{array}{l}V C \\
\text { (\% predicted) }\end{array}$ & $F E V_{1}$ & $F E V_{1} / V C \%$ & $\begin{array}{l}T_{L C O} \\
\left(m l \min ^{-1}\right. \\
\left.\operatorname{mm} H_{g}^{-1}\right)\end{array}$ & $\begin{array}{l}T_{L c o} \\
\text { (\% predicted) }\end{array}$ \\
\hline $\begin{array}{r}1 \\
2 \\
3 \\
4 \\
5 \\
6 \\
7 \\
8 \\
9 \\
10 \\
11\end{array}$ & $\begin{array}{l}25 \\
32 \\
23 \\
32 \\
48 \\
28 \\
21 \\
22 \\
30 \\
42 \\
43\end{array}$ & $\begin{array}{l}\mathbf{F} \\
\mathbf{F} \\
\mathbf{F} \\
\mathbf{M} \\
\mathbf{M} \\
\mathbf{F} \\
\mathbf{F} \\
\mathbf{F} \\
\mathbf{M} \\
\mathbf{M} \\
\mathbf{F}\end{array}$ & $\begin{array}{l}2.03 \\
1.34 \\
2.76 \\
3.02 \\
2.54 \\
1.00 \\
1.31 \\
2.10 \\
1.97 \\
2.13 \\
2.50\end{array}$ & $\begin{array}{l}56 \\
39 \\
73 \\
71 \\
65 \\
26 \\
38 \\
55 \\
41 \\
41 \\
69\end{array}$ & $\begin{array}{l}1.79 \\
0.99 \\
1.99 \\
2.38 \\
2.07 \\
0.74 \\
0.89 \\
1.65 \\
1.10 \\
1.92 \\
1.83\end{array}$ & $\begin{array}{l}88 \\
74 \\
72 \\
79 \\
81 \\
74 \\
68 \\
79 \\
56 \\
90 \\
73\end{array}$ & $\begin{array}{r}7.3 \\
13.7 \\
15.1 \\
18.2 \\
12.1 \\
5.2 \\
8.0 \\
9.6 \\
17.8 \\
13.1 \\
9.8\end{array}$ & $\begin{array}{l}27 \\
62 \\
55 \\
60 \\
39 \\
20 \\
36 \\
38 \\
52 \\
37 \\
38\end{array}$ \\
\hline
\end{tabular}

VC-vital capacity; FEV $_{1}$-forced expiratory volume in one second; TLo-transfer factor for carbon monoxide (diffusing capacity).

Conversion: Traditional to SI units-TLo: $1 \mathrm{ml} \mathrm{min}^{-1} \mathrm{~mm} \mathrm{Hg}^{-1}=\approx 3 \mathrm{mmol} \mathrm{min}^{-1} \mathrm{kPa}^{-1}$.

capacity (VC) was normal or supranormal in all but two patients, suggesting that there was no appreciable obstructive component. The patients were asked to come to the lung function laboratory several times a week for serial measurements of vital capacity. The initial dose of steroid was maintained at least until the peak vital capacity was reached and maintained. All patients were being treated for sarcoidosis for the first time except for patient 3 , who had received corticosteroids three years previously and required repeat treatment because of relapse. Patient 5 was treated and studied twice.

\section{Results}

All patients showed prompt improvement of vital capacity after the start of corticosteroid treatment. The course of this improvement is shown in the figure. As can be seen, measurements showed improvement within 10 days and the peak value was approached within three weeks. The time course of this response was no different for the two patients who received a second course of treatment.

\section{Discussion}

We have shown that in this group of patients steroids led to prompt improvement of vital capacity, so that a beneficial effect could always be detected within three weeks. This may be useful in deciding whether or not a steroid response is present, and if no improvement occurs within this period treatment may be discontinued. Webb and associates ${ }^{7}$ performed similar studies of the effects of prednisolone in patients with chronic obstructive pulmonary disease. Their data, indicating that steroids produced a maxi- mal effect within eight days, have been extremely useful in guiding physicians in the use of corticosteroids in that condition. Similar guidelines may result from the present study. Although a larger number of patients would need to be studied to give absolute certainty that a response would not occur after a longer period of time, the consistency of the data presented suggests that this would be very unlikely. Our data confirm our clinical impression that, in patients deemed likely to respond, pulmonary function in sarcoidosis improves rapidly after institution of treatment with corticosteroids.

\section{References}

1 Sharma OP, Colp C, Williams MH jun. Course of pulmonary sarcoidosis with and without corticosteroid therapy as determined by pulmonary studies. $\mathrm{Am} \mathrm{J} \mathrm{Med}$ 1966;41:541-51.

2 Williams MH jun. Pulmonary function in sarcoidosis. In: Fanburg BL, ed. Sarcoidosis and other granulomataous disease of the lung. New York: Marcel Dekker, 1983:77-98.

3 Selroos O, Sellergren TL. Corticosteroid therapy of pulmonary sarcoidosis. Scand J Respir Dis 1979;60: 215-21.

4 Johns CJ, Zachary JB, Ball WC jun. A 10-year study of corticosteroid treatment of pulmonary sarcoidosis. Johns Hopkins Med J 1974;134:271-83.

5 Emirgil C, Sobol BJ, Williams MH jun. Long term study of pulmonary sarcoidosis. J Chron Dis 1969;22:69-86.

6 Colp C, Park SS, Williams MH jun. Pulmonary function follow-up of 120 patients with sarcoidosis. Ann NY Acad Sci 1976;278:301-7.

7 Webb J, Clark TJH, Chilvers C. Time course of response to prednisolone in chronic airflow obstruction. Thorax 1981;36:18-21. 